\title{
How Can Environmental Impacts of Water Demand Management Policies on a Wastewater System be Assessed?
}

\section{Haniye Safarpour}

University of Tehran College of Engineering

Massoud Tabesh ( $\nabla$ mtabesh@ut.ac.ir)

University of Tehran https://orcid.org/0000-0002-8982-8941

Seyyed Ahmadreza Shahangian

University of Tehran College of Engineering

\section{Research Article}

Keywords: Life Cycle Assessment, Urban Water Management, Wastewater Collection Network, Wastewater Treatment Plant, Environmental Impacts, SimaPro software

Posted Date: January 31st, 2022

DOl: https://doi.org/10.21203/rs.3.rs-1269470/v1

License: (c) (i) This work is licensed under a Creative Commons Attribution 4.0 International License. Read Full License 


\section{Abstract}

As applying water demand management policies (WDMPs) can affect urban water infrastructures like wastewater systems from various aspects, this study proposes a novel approach to address the environmental impacts of applying WDMPs for the first time. Baharestan city, in Iran's Isfahan province, is considered as a case study where various WDMPs, such as public awareness campaigns and water pressure management, are applied to confront water scarcity and to reduce water demand. To this end, the life cycle assessment (LCA) method is used to assess the environmental burdens of utilizing WDMPs in the operation stage of a real wastewater collection network (WWCN) and wastewater treatment plant (WWTP) under different WDMPs. A detailed inventory is considered, including detailed repairing of sewer pipelines and their maintenance, replacement of manhole covers, civil works, road rehabilitation, energy consumption, chemical usage, transportation, and air emissions of both the WWCN and WWTP, in various phases. The environmental assessment is conducted in SimaPro software using the ReCipe method. Based on results, a significant part of the environmental impacts accounts for energy consumption which has strong effects on most midpoint categories and has a great change in different scenarios. Besides, the results demonstrate that the environmental effects driven by the WWTP are eightfold the corresponding WWCN's impacts. Overall, the outcomes from the present study revealed that implementing WDMPs can lead to diminishing environmental impacts. For instance, reducing wastewater production up to $68 \%$ can decrease $18 \%$ of the WDMPs' environmental impacts of the wastewater system in the operation stage.

\section{Introduction}

Although freshwater is crucial to human survival, economic growth, and ecosystem service provision (Shahangian et al. 2021b), ensuring water security has currently emerged as a crucial policy challenge that water utilities will meet in the future (Shahangian et al. 2021a, b). Over the past years, rapid urban population growth and climate change, as the main drivers of water scarcity, led policymakers to adopt strategies to control or reduce water consumption (Ramsey et al. 2017; Hsien et al. 2019). While effectively managing urban water systems is of paramount importance (Shahangian et al. 2021b), it has become a critical policy challenge for public services in these environs, where are particularly at risk of water scarcity (Stavenhagen et al. 2018; Shahangian et al. 2021b). Urban water demand management, as a necessity for sustainable water supplies (Stephan and Stephan 2017; Shahangian et al. 2021a) and an essential element of sustainable water management (Shahangian et al. 2021b), is one of these approaches which comprises different policies such as public awareness campaigns, water-efficient appliances, and greywater recycling (Ratnasiri et al. 2017; Stavenhagen et al. 2018; Goette et al. 2019). Implementing such policies, depending on the type of the policy, could generally have vast positive and negative consequences which affect urban water infrastructures (Shahangian et al. 2020), including water treatment plants, water distribution networks, wastewater collection networks (WWCNs), and wastewater treatment plants (WWTPs) (Sun et al. 2015; Marleni et al. 2015; Bailey et al. 2019). During past years, studies have mainly focused on assessing the effects of water demand management policies 
(WDMPs) on potable water systems (e.g., Marinoski et al. 2018; Liu and Mukheibir 2018), and consequently, the influence of those policies on wastewater systems has been considered just in limited studies (e.g., Opher and Friedler 2016).

Several studies have investigated different aspects of applying WDMPs on one or more than one part of the urban water services, and they solely represented a percentage of water consumption reduction (Willis et al. 2013; Quesnel and Ajami 2017; Stephan and Stephan 2017; Liu and Mukheibir 2018). Some researchers reported the consequences of applying WDMPs on reducing wastewater production in addition to water consumption reduction (DeZellar and Maier 1980; Parkinson et al. 2005), which can make changes in the performance and flow conditions in WWCNs. Hydraulic parameters of WWCNs are affected by changes in wastewater flow, to the extent that reducing sewage discharge leads to lower flow velocities, increased sedimentation, and diminished wastewater depth in pipelines (Parkinson et al. 2005; Bailey et al. 2019). In addition, evaluation of wastewater quality parameters was conducted under implementing different WDMPs in some previous studies, revealed that the concentration of BOD, TSS, and other pollutants would increase (DeZellar and Maier 1980; Marleni et al. 2015; Bailey et al. 2019). Thus, increasing the concentration of qualitative parameters and decreasing flow velocities lead to a higher amount of gas emissions in WWCNs, especially emission rates of $\mathrm{CH}_{4}$ and $\mathrm{H}_{2} \mathrm{~S}$ (Sun et al. 2015; Marleni et al. 2015) that can have negative environmental impacts. Although the effects of WDMPs on WWTPs have not been discussed in any previous research, considering its mentioned consequences on WWCNs, it can be expected that applying WDMPs can influence some parts or a whole WWTP.

Although assessing the environmental impacts of any decision is a crucial, up-to-date, and global issue (ISO 1997), there is a lack of environmental assessment in some domains of research and decisionmaking, specifically in WDMPs. Indeed, few studies have assessed the environmental effects of WDMPs on water distribution networks (Kalbusch and Chisi 2016; Jeong et al. 2016; Marinoski et al. 2018), and only a handful of research has considered the environmental impacts of WDMPs on wastewater systems, as the review research by Mannan and Al-Ghamdi (2020) confirms. For instance, Opher and Friedler (2016) evaluated the environmental impacts of four greywater reuse scenarios which their results revealed the positive environmental effects of WDMPs on the wastewater system. They used Life Cycle Assessment (LCA) method as a technique for analyzing environmental impacts thorough the system's lifetime. This method is highly applied in different water environment research (Xiong et al. 2020). Since most studies on WDMPs' environmental impacts using the LCA method (such as Petit-Boix et al. (2018); Hsien et al. (2019)) only considered reuse, recycling, and rainwater harvesting as policies for confronting water scarcity, it should be noted that effects of other WDMPs, like water pressure management, not only on water systems but also on wastewater systems are as important to assess as the mentioned policies' environmental impacts.

Among previous research that has addressed the environmental impacts of wastewater systems using LCA, some of them focused on either WWCNs (Petit-biox et al. 2015; Petit-biox et al. 2016; Morera et al. 2016; Kyung et al. 2017; Sharma and Rao 2018), or WWTPs (Lopes et al. 2018; Resende et al. 2019; Tabesh et al. 2019; Awad et al. 2019), and fewer studies addressed both (Slagstad and Brattebø 2014; 
Risch et al. 2015; Xue et al. 2019). Within such a growing body of literature, some scholars considered various stages like the construction and operation (Slagstad and Bratteb $\emptyset$ 2014; Risch et al. 2015; Morera et al. 2016; Kyung et al. 2017; Lopes et al. 2018; Jin 2019), and some of them have only concentrated on a specific stage of the system's life cycle including construction, operation, and end of life (Petit-biox et al. 2015; Petit-biox et al. 2016; Sharma and Rao 2018; Tabesh et al. 2019).

Risch et al. (2015) applied the LCA method for assessing the environmental burdens of a WWCN and WWTP using comprehensive inventory data. They considered energy consumption, air emission of gases, and sewer leakage in the operation stage. Their results demonstrated a significant proportion of environmental impacts of the sewer network in comparison with the WWTP. Also, Slagstad and Bratteb $\varnothing$ (2014) used the LCA method for a water and wastewater system considering the construction and operation stages. However, the effects caused by constructing roads (asphalt layer) and manholes, repairing pipelines, and replacing manhole covers were neglected in this research. Contrary to Risch et al. (2015), the study results by Slagstad and Bratteb $\varnothing$ (2014) suggested that the environmental impacts of a WWTP are more than a WWCN.

Lopes et al. (2018) evaluated the environmental impacts of construction and operation stages of a WWTP during 20 years. They considered air emissions, energy, and chemical consumption over the operation stage, while the transportation of sludge and other effluents was excluded in their study. In addition, Petit-biox et al. (2015) analyzed the operation stage of a sewer network, considering the energy used in different parts and materials required for repairing damages from a life cycle perspective. They omitted the transportation and energy consumption of the pump station. Their results showed the importance of sewer network pumping in environmental assessment. Tabesh et al. (2019) also analyzed the environmental effects of the operation stage of a WWTP using LCA. They considered air emissions as well as energy and chemicals used in different parts of WWTP as an inventory.

Summing up from the literature review, only a handful of research considered the impacts of applying WDMPs on wastewater systems. These studies have been primarily focused on analyzing the changes in qualitative, quantitative, and hydraulic parameters of the sewer networks, and there is no evidence to address the impacts of applying WDMPs on WWTPs from different aspects. Also, there is still a large research gap in assessing the environmental impacts of WDMPs, other than reuse and recycling of greywater and rainwater harvesting, on wastewater systems through a detailed inventory dataset, which was neglected in previous studies. Moreover, limited research addressed the environmental impacts of both WWCNs and WWTPs simultaneously. Besides, only a few studies focused on the environmental effects of wastewater systems in the operation stage. Hence, this study attempts to bridge all the abovementioned research gaps by assessing the environmental impacts of implementing WDMPs on a real wastewater system in the operation stage through a novel approach using the LCA method and considering a detailed data inventory.

\section{Methodology}


LCA is a practical and helpful tool with a global point of view for addressing the environmental aspects throughout a product or service's life cycle. LCA allowed the quantification of the system's environmental effects, such as global warming and fossil resource scarcity. This method includes four main steps: (1) Definition of goal and scope, which specifies the system boundaries and aim of the research; (2) Providing Life Cycle Inventory ( $\mathrm{LCl}$ ), which encompasses the collection of different types of data (inputs and outputs) considered in the system boundaries; (3) Life Cycle Impact Assessment (LCIA), in which the collected data are assessed based on the assessment methods and LCA software (ReCipe method in SimaPro software is used in the current study); and (4) Interpretation of results (ISO 2006; GallegoSchmid et al. 2019; Corominas et al. 2020). In the following sub-sections, the steps of the LCA are presented, which align with ISO standards used to assess the environmental impacts of WDMPs on the wastewater system.

\subsection{Goal and scope definition}

The main goal of the present research is an integrated assessment of the environmental impacts resulting from implementing different real and hypothetical scenarios of applying WDMPs on a real wastewater system, including both the WWCN and the WWTP, in the operation stage. To this end, as a novel starting point in studying WDMPs impacts on urban infrastructures, a thorough LCA is conducted via a detailed inventory of data on the wastewater system. In this regard, the following objectives are considered:

- Evaluating the environmental impacts of different scenarios by applying WDMPs (e.g., water-efficient appliances)

- Identifying hotspots by comparing the environmental impacts of different phases considered for both the WWCN and WWTP.

- Highlighting the environmental contribution of the WWCN and the WWTP to the wastewater system.

- Providing a thorough inventory of material, transportation, machinery, air emissions, energy, and chemical for the operation stage.

To compare the environmental consequences of implementing WDMPs which are a combination of different scenarios on the wastewater system, a whole life cycle of this system is modeled. The timeframe of the assessment is several years into the future, until the end of 2036. System boundaries contain the process and activities included in LCA (ISO 2006). In defining the system boundary, the main objective is how to choose the process and parts of the life cycle that are relevant to the aim of the study (Corominas et al. 2020). Considering the purpose of this study, only the environmental impacts of applying WDMPs on the existing wastewater system in its operation stage are therefore considered. Consequently, the system's installation and end of life stages are neglected. This is in line with studies conducted by Petit-Boix et al. (2015) and Piao et al. (2016), in which only the operation stage is noticed. In this paper, the operation stage of the wastewater system includes gas emissions to air, network 
failures, electricity usage, chemical consumption, and transportation. The system boundary of the WWCN and WWTP's phases are shown in Fig. 1(a) and Fig. 1(b), respectively.

The functional unit (FU) that is used to determine the inputs and outputs in the LCA method must be commensurate with the aim of the study and the system boundaries (ISO 2006). Therefore, various types of FU can be chosen, such as per capita and pollution load (Hajibabaei et al. 2018; Corominas et al. 2020). Regarding the defined goal and scope in the present research, FU has been considered $1 \mathrm{~m}^{3}$ of wastewater discharged into the WWCN, treated in the WWTP, and finally goes out as effluent and sludge. The defined FU is constant in different scenarios. The final results will also be changed by the whole wastewater production volume in the system's lifetime. The considered lifespan for both the WWTP and the WWCN is assumed to be 19 years (from 2018 to 2036) based on their real lifespan in the case study.

\subsubsection{Case study and compared scenarios}

Using a real case study (Baharestan), the applicability of the presented novel approach was examined to evaluate the environmental effects of applying WDMPs on the wastewater system. Baharestan is a city with 86011 inhabitants in 2018, located in Isfahan province, Iran (the location of the case study is provided in the supplementary information (SI)). The Baharestan's gravity sewer system was made of HDPE pipes with a minimum $200 \mathrm{~mm}$ diameter. Stormwater is collected in a separate pipeline system, which is not in the defined system boundary. The central wastewater treatment plant comprises primary, secondary, and complementary treatment (Further information about the type of wastewater treatment used in this work can be found in the SI). The solid residue for disposal from the wastewater system is transferred to landfills. The effluent is also discharged into the artificial lake near the town, and the sludge is transferred to the depot site. Due to severe drought and water scarcity in Isfahan province (Gohari et al. 2013; Pishyar et al. 2018) and the high population growth rate in Baharestan city, water pressure management has been applied since 2018 to reduce water consumption by decreasing the water distribution network's pressure to a lower than the desired range, as one of the WDMPs in this city.

The difference between per capita sewage production caused by reducing water demand under related WDMPs is considered in separate scenarios listed below.

- Scenario 0 (base scenario): In this scenario, the sewage production is considered 165.4 liters per person per capita per day (Ipcd), which is the average of the last seven years in the case study. This scenario does not include any reduction in wastewater production, where only the population growth rate is considered. Indeed, it is assumed that no WDMPs are applied.

- Scenario 1: This scenario that is representative of the current situation of the study area involves water pressure management and awareness-raising and educational campaigns. Based on Baharestan water and wastewater utility (2019), the implementation of this scenario has been reduced $8.84 \%$ of water demand, and consequently, sewage production during the first year. Besides, given the report of Isfahan Water and Wastewater Company (2019), it is expected that wastewater 
will be reduced by $20 \%$ during ten years. Therefore, the maximum long-term reduction percentage in this scenario is assumed to be $20 \%$.

- Scenario 2: This scenario considers situations in which households adopt water-efficient appliances by raising awareness about these fixtures. The previous research has revealed that this policy that aimed to promote household appliance utilization might reduce water consumption by 10 to 50 percent (Parkinson et al. 2005; Marleni et al. 2015; Sun et al. 2015; Shahangian et al. 2021a). By reviewing the previously published literature in this field, the final reduction percentage is considered $30 \%$ at the end of the system's lifetime. It should be noted that all households would not accept this policy simultaneously. Thus, it has been assumed that households adopt water-efficient appliances over time by raising public awareness. As a result, the percentage of wastewater reduction starts at $10 \%$ in the first year and will reach $30 \%$ at the end of the system's lifetime.

- Scenario 3: Water tariff reform is a way to reduce water consumption. In this regard, studies demonstrated that by modifying the water price structure, the consumption of water and production wastewater could decrease between 15 to 36 percent (Tanverakul and Lee 2015; Lopez-Nicolas et al. 2018; Ratnasiri et al. 2018). This scenario is case-specific and depends on social and economic conditions. In this paper, $8 \%$ is considered as the average percentage of water consumption reduction for the first year, reaching $18 \%$ in 19 years.

- Scenario 4: This scenario is a hypothetical combination of the above scenarios applied to highlight the environmental effects of applying WDMPs on the wastewater system, making it easier to compare the results. Therefore, considering a more significant reduction percentage to demonstrate the impacts of applying WDMPs on water consumption reduction above the growing population rate could be helpful.

Table 1 shows the trend of wastewater production per capita in every scenario and different periods until the end of the system's lifetime. In this table, the highest reduction percentage in wastewater production is $68 \%$ (from 163.39 lpcd in 2016 to 52.28 lpcd, average of 94 lpcd) by 2036, which occurred in the hypothetical scenario 4. 
Table 1

Population growth and wastewater production reduction in every scenario

\begin{tabular}{|c|c|c|c|c|c|c|c|}
\hline \multicolumn{2}{|c|}{ Changes during the years } & \multirow{2}{*}{$\begin{array}{l}2017 \\
82541\end{array}$} & \multirow{2}{*}{$\begin{array}{l}2018 \\
86011\end{array}$} & \multirow{2}{*}{$\begin{array}{l}2021 \\
96420\end{array}$} & \multirow{2}{*}{$\begin{array}{l}2026 \\
113769\end{array}$} & \multirow{2}{*}{$\begin{array}{l}2031 \\
131118\end{array}$} & \multirow{2}{*}{$\begin{array}{l}2036 \\
148467\end{array}$} \\
\hline $\begin{array}{l}\text { All } \\
\text { scenarios }\end{array}$ & Population & & & & & & \\
\hline \multirow{2}{*}{$\begin{array}{l}\text { Scenario } \\
0\end{array}$} & Reduction percentage & 0 & 0 & 0 & 0 & 0 & 0 \\
\hline & $\begin{array}{l}\text { Average } W^{\star} W^{\star} \\
\text { production }\left(\operatorname{lpcd}^{\star \star}\right)\end{array}$ & 165.4 & 165.4 & 165.4 & 165.4 & 165.4 & 165.4 \\
\hline \multirow{2}{*}{$\begin{array}{l}\text { Scenario } \\
1\end{array}$} & Reduction percentage & 0 & 8.84 & 15 & 18 & 20 & 20 \\
\hline & $\begin{array}{l}\text { Average WW } \\
\text { production (Ipcd) }\end{array}$ & 163.39 & 148.95 & 138.88 & 133.98 & 130.71 & 130.71 \\
\hline \multirow{2}{*}{$\begin{array}{l}\text { Scenario } \\
2\end{array}$} & Reduction percentage & 0 & 10 & 15 & 20 & 25 & 30 \\
\hline & $\begin{array}{l}\text { Average WW } \\
\text { production (Ipcd) }\end{array}$ & 163.39 & 147.05 & 138.88 & 130.71 & 122.54 & 114.37 \\
\hline \multirow{2}{*}{$\begin{array}{l}\text { Scenario } \\
3\end{array}$} & Reduction percentage & 0 & 8 & 10 & 13 & 15 & 18 \\
\hline & $\begin{array}{l}\text { Average WW } \\
\text { production (Ipcd) }\end{array}$ & 163.39 & 150.32 & 148.05 & 142.15 & 138.88 & 133.98 \\
\hline \multirow{2}{*}{$\begin{array}{l}\text { Scenario } \\
4\end{array}$} & Reduction percentage & 0 & 27.84 & 40 & 51 & 60 & 68 \\
\hline & $\begin{array}{l}\text { Average WW } \\
\text { production (Ipcd) }\end{array}$ & 163.39 & 117.90 & 98.03 & 80.06 & 65.36 & 52.28 \\
\hline \multicolumn{8}{|c|}{${ }^{*}$ Wastewater } \\
\hline \multicolumn{8}{|c|}{${ }^{\star \star}$ Ipcd stands for liters per person per capita per day } \\
\hline
\end{tabular}

\subsection{Inventory analysis}

Based on the collected data, all the inputs and outputs needed for the LCA of a system (e.g., materials and processes) are quantified. To reach this goal, a list of the inventory related to the operation stage of the wastewater system was prepared. The required data is mainly obtained from Baharestan city's water and wastewater utility. Secondary data, as well as missing primary data, was also achieved using scientific literature, interviews, and site visits. In addition, Ecoinvent 3.5 database was used for modeling sub-process data.

\subsubsection{Life Cycle Inventory (LCI) of WWCN}

In the operation stage of the WWCN, replacing defective manhole covers (including materials, construction of covers, transportation, and installation), unclogging sewer pipes and manholes, repairing sewer pipes failures (including excavation, backfilling, compacting, etc.), reconstruction of the asphalt 
layer, and gas emissions to air including $\mathrm{CH}_{4}$ and $\mathrm{H}_{2} \mathrm{~S}$, are considered. Average $\mathrm{H}_{2} \mathrm{~S}$ and $\mathrm{CH}_{4}$ concentrations were estimated through the equations introduced by Tee et al. (2011) and Chaosakul et al. (2014), respectively (the equations can be found in SI). It is worthwhile to note that the hydraulic parameters driven by hydraulic modeling for every sewer pipe were used in mentioned equations to calculate gas production. The data collected from the sewer network in the operation stage is categorized into four separate phases.

- First, sewer blockage phase: This phase contains blockage in the main sewer pipelines, siphon of the sewer branch pipes, and manholes. The blockage rate in sewer pipelines (main and branches) differs based on the amount of wastewater inflow to the network. In other words, more reduction in wastewater flow leads to more blockages, which mostly occurs because of lower velocities in pipelines and more sedimentation. Due to the lack of data collected from Baharestan water and wastewater utility for manhole blockage, the rate of this one was considered fixed in different scenarios.

- Second, manhole cover replacement phase: For this phase, the fixed annual rate of manhole replacement is considered for different scenarios. Manhole covers are made of both cast iron or reinforced concrete. The main reasons for manhole cover replacement are breakage and missing.

- Third, asphalt layer and repairing pipeline breakage: There are situations where the asphalt layers (two different layers are considered) of the old trenches are destroyed and repaired. It should be noted that repairing the breakage in pipelines needs excavation, backfilling, compacting, and installing new asphalt layers. The annual rate of this phase is considered fixed in all scenarios.

- Fourth, gas emission phase: This phase is the average gas emissions to the air from the WWCN, including $\mathrm{H}_{2} \mathrm{~S}$ and $\mathrm{CH}_{4}$. The concentration of these gases differs in scenarios depending on the wastewater inflow.

\subsubsection{Life Cycle Inventory (LCI) of WWTP}

In the operation stage of the WWTP, energy, chemicals, transportation, and gas emissions, including $\mathrm{CO}_{2}$, $\mathrm{CH}_{4}$, and $\mathrm{N}_{2} \mathrm{O}$, are considered. Considering the lack of data, $\mathrm{CO}_{2}$ and $\mathrm{CH}_{4}$ were estimated using EPA (2010) equations, and the amount of $\mathrm{N}_{2} \mathrm{O}$ produced in a WWTP is regarded as $3.2 \mathrm{gr} / \mathrm{person} / \mathrm{year}$ as IPCC (2006) stated (further information is available in the SI). Similar to the WWCN, four separate phases are considered for the WWTP in the operation stage as follows:

- First, energy phase: Considering changes in wastewater production, the amount of energy consumption differs in every scenario according to wastewater inflow.

- Second, chemical usage: The only chemical used in this WWTP is the polymer, used as the coagulant, which is affected just by population. The mass of input contamination per person per day is fixed, so the amount of chemical use does not differ in scenarios. Considering that UV lamps are used for disinfection in this WWTP, there is no chlorine usage. 
- Third, transportation: This phase includes transportation of chemicals to the plant, carrying garbage to the landfill, transportation of treated wastewater to the artificial lake for further usage, and transportation of sludge to the depot site. This phase differs in each scenario.

- Fourth, the gas emissions phase: Direct gas emissions generated during the WWTP operation are $\mathrm{CH}_{4}, \mathrm{CO}_{2}$, and $\mathrm{N}_{2} \mathrm{O}$, and due to the lack of data, it is supposed that their amount only relies on wastewater volume that alters in different scenarios. The importance of considering gas emissions in an inventory of a WWTP's life cycle assessment is highlighted by Rodriguez-Garcia et al. (2012).

\subsection{Life cycle impact assessment}

The LCA method considers all inputs and outputs mentioned in the previous step to evaluate the environmental impacts of the system. For this purpose, SimaPro v9.0 software and Ecoinvent v3.5 database are used to model and assess the environmental impacts. In this article, the ReCiPe $2016 \mathrm{v} 1.1$ method, which is consists of midpoint and endpoint impacts, is applied. Midpoint indicators, including ozone formation, fine particulate matter formation, human health, stratospheric ozone depletion, ionizing radiation, human non-carcinogenic toxicity, human carcinogenic toxicity, water consumption, global warming, ozone formation, freshwater eutrophication, terrestrial ecosystems, terrestrial acidification, terrestrial ecotoxicity, marine eutrophication, freshwater ecotoxicity, marine ecotoxicity, mineral resource scarcity, land use, and fossil resource scarcity, helped to inspect the selected phases. Furthermore, for easier decision-making and comparison between different scenarios, the ReCipe endpoint method is adopted, in which environmental impacts are categorized, normalized, and weighted to a dimensionless number (point). Finally, indicators are aggregated into three main categories: human health, ecosystem, and resources (ReCipe 2016).

\section{Results}

\subsection{Comparing the environmental midpoint impacts of different phases in the WWCN}

The environmental impacts of applying WDMPs on the WWCN in four different phases, explained in section 2.2.1, are compared via eighteen separate midpoint categories. Fig. 2 illustrates the environmental impacts of various phases of the WWCN in the base scenario, scenario 1 (current situation), scenario 2 , scenario 3 , and scenario 4 (with the maximum reduction in wastewater flow), respectively. Further and extended comparisons are conducted between the base scenario and scenario 4 , which have the maximum difference in wastewater production. The numerical results of the other scenarios can be found in SI. Based on the results, the gas emissions phase has a significantly higher impact on global warming. Although the concentration of pollutants in scenario 4 is more than the base scenario, there are fewer environmental effects of gas emissions, due mainly to a significant decrease in wastewater inflow. 
Comparing Fig. 2(a) to Fig. 2(e) shows that decreasing wastewater production volume leads to an increase in environmental impacts of applying WDMPs in the blockage phase. For instance, considering that a Waterjet machine is used to unclog the blockages in the main pipelines, the growth of the blockage rate makes an increase in water consumption from approximately $34 \%$ (around $3800 \mathrm{~m}^{3}$ ) in the base scenario to roughly $54 \%$ (about $8700 \mathrm{~m}^{3}$ ) in scenario 4 . Material, construction, transportation, and installation of manhole covers emphasize the critical role of the manhole cover phase in most midpoint categories. Despite the nominal environmental impacts rate of asphalt and repairing broken pipes, its environmental effects cannot be ignored. In this regard, previous studies highlighted the importance of the asphalt layer in road construction, too (Hajibabaei et al., 2020). The quantitative results of global warming category as one of the most important issues around the world have been described in the following sub-section.

\subsubsection{Global warming}

The environmental impacts of gas emissions associated with the global warming midpoint category per $\mathrm{FU}$ increase from around $53.5 \mathrm{gr} \mathrm{CO}_{2}$ eq./ $\mathrm{m}^{3}$ in the base scenario to approximately $54.1 \mathrm{gr} \mathrm{CO}_{2}$ eq. $/ \mathrm{m}^{3}$ in scenario 4. This is mainly because of an increase in pollutant concentrations. However, in general, the global warming numerical impacts of overall gas emissions have decreased from 7.2 million $\mathrm{kg} \mathrm{CO}_{2}$ eq. in the base scenario with an average of $165.4 \mathrm{lpcd}$ to around 3.4 million $\mathrm{kg} \mathrm{CO}_{2}$ eq. in scenario 4 with an average of $94 \mathrm{lpcd}$ of wastewater production during 19 years. Such a decrease in overall impacts is due mainly to the fact that the influence of a significant reduction in wastewater production overcomes the effects of an increase in the concentration of pollutants. Further detailed information about the WWCN's gas emissions and their environmental burdens could be found in Safarpour et al. (2021). Risch et al. (2015) reported that direct gas emissions from a WWCN do not contribute significantly to overall LCA results, while the results of the present study are opposite. The probable reason for this difference is that their study included the construction stage, while the gas emissions phase mostly contributes to the operation stage.

\subsection{Comparing the environmental midpoint impacts of different phases in the WWTP}

The environmental impacts of implementing WDMPs on the WWTP in the operation stage in different phases from scenarios 0 to 4 are depicted in Fig. 3 using separate midpoint categories. Energy consumption is one of the most significant parts of water and wastewater systems, which has great environmental impacts (Beygi et al. 2021). As shown in Fig. 3, the energy consumption phase has a more considerable contribution to most midpoint impact categories, in line with Akhoundi and Nazif (2020). Furthermore, the amount of energy consumption decreases in scenario 4 in comparison with the base scenario. The impact of the energy phase on the global warming is reduced from around 18.4 million $\mathrm{kg}$ $\mathrm{CO}_{2}$ eq. to 8.5 million $\mathrm{kg} \mathrm{CO}$ eq. from scenario 0 to scenario 4 with an average wastewater production of 165.4 to 94 Ipcd during 19 years, respectively. 
The gas emissions phase has considerable effects on stratospheric ozone depletion and global warming categories because gases such as $\mathrm{CO}_{2}, \mathrm{CH}_{4}$, and $\mathrm{N}_{2} \mathrm{O}$ have a high global warming potential (IPCC 2014), which is considered in the assessment of the environmental impacts of the current study. Moreover, the transportation phase significantly affects a specific midpoint category (i.e., land use). Considering the reduction in treated wastewater effluent amount, the environmental impacts of the transportation phase reduce approximately $52 \%$ from the base scenario to scenario 4 .

\subsection{Comparing the environmental impacts between the WWCN and WWTP}

The endpoint impact categories of the WWTP in comparison with the WWCN are illustrated in Fig. 4. The LCA results demonstrate that the WWTP has more significant environmental effects than the WWCN in the operation stage, in line with Slagstad and Brattebø (2014), to the extent that the environmental impacts of the WWTP are approximately eightfold the WWCN. One of the most influential phases of the WWTP is energy consumption, which affects the overall results as well and makes the WWTP's environmental impacts higher than the WWCN. As depicted in Fig. 4, human health mostly contributes to the endpoint impact categories, which accounts for approximately $90 \%$ of total environmental impacts for both the WWCN and WWTP in every scenario. Indeed, it can be seen in the results that most inventory data are dangerous for human health. Also, the weight of midpoint categories which contribute to human health is higher than the weight of them for other endpoint categories. As observed in Fig. 4, the environmental effects of applying WDMPs decreased by reducing wastewater production, which can lead to positive influences on both the WWCN and the WWTP from the environmental perspective.

\subsection{Comparing the environmental impacts of different scenarios}

Although the reduction in wastewater production and population growth have reverse effects, the overall environmental impacts of applying WDMPs on the wastewater system are reduced (Shown in Fig. 5). Sequences of different scenarios of WDMPs in human health category of endpoint impacts groups are as follows: base scenario $(1.81 \mathrm{Mpt})>$ scenario $3(1.71 \mathrm{Mpt})>$ Scenario 1 (1.68 Mpt)> scenario 2 (1.66 Mpt)> scenario 4 (1.48 Mpt). The same is true for the other categories (ecosystem and resources). The results of scenarios 1 and 2 are close because of the proximity of their wastewater reduction percentage. The LCA results showed that the scenario with the maximum reduction percentage is the best in terms of environmental impacts assessment, in line with Opher and Friedler (2016).

\section{Discussion And Conclusions}

This study is conducted with the aim of assessing the environmental effects of implementing WDMPs on a real WWCN and WWTP in the operation stage of the system. To reach this purpose, a comprehensive inventory of gas emissions, chemical and energy consumption, repairing pipes, manhole covers, and transportation is considered. The LCA method is applied to the assessment in order to compare various scenarios with different amounts of wastewater production. In this regard, SimaPro software, ReCipe 
midpoint and endpoint method is used. The overall results show that applying WDMPs could reduce the environmental burden of the wastewater system, which is an important issue in today's world. To explain more, the environmental impacts of applying WDMPs on the wastewater system decrease $18 \%$ from the base scenario to scenario 4 with a $68 \%$ reduction in wastewater production. As the numerical results of the assessment show, in the WWCN, the manhole cover phase has significant environmental impacts that are neglected in previous studies. To explain, the raw material for manholes, as well as the construction, transportation, and installation process, played a significant role in the environmental burdens.

It is essential to consider the repair of the network's breakages and blockages. A major challenge in this case study was the pipeline blockages. The blockages in pipelines increase by reducing wastewater inflow, the reduced velocity of discharges in pipes, and augmentation of sedimentation. Therefore, the environmental impacts of this phase increase in scenarios with lower wastewater inflow. The results emphasize that bitumen paving which is ignored in most previous studies, should be considered in the LCA of sewer systems, even in small amounts of the asphalt layer. Also, the results show gas emission was a crucial phase in the operation stage of the WWCN. The concentration of $\mathrm{BOD}_{5}$, wastewater quantity, velocity in pipes, and wastewater retention time in pipelines change the amount of gas production in alternative scenarios. The gas emission phase mainly influences the global warming midpoint category. The total environmental burden of this phase reduced $53 \%$ in around $68 \%$ of inflow reduction (from scenarios 0 to 4). The energy consumption in the operation stage of the wastewater system was the most significant phase. The environmental effects of this phase were reduced around $54 \%$ from the base scenario to scenario 4 (with the maximum inflow reduction).

Moreover, results demonstrate that the environmental impacts of the WWTP are approximately eight times greater than the WWCN in the operation stage. In the end, the total environmental impacts of WDMPs in scenarios are as below: Scenario $0>$ scenario $3>$ scenario $1>$ scenario $2>$ scenario 4 . In other words, a scenario with lower wastewater quantity had lower environmental impacts. Thus, from an environmental standpoint, scenario 4 has the best performance, but is this scenario perfect from other perspectives, too? Therefore, it is recommended to consider other aspects of applying WDMPs on wastewater systems, such as social and economic aspects, to reach a more particular viewpoint. Also, the supposed case study's wastewater system is a new one, and there is no data of the system's renovation stage. Therefore, it is recommended for future studies to take into account the renovation stage and make the system boundary wider, which could affect the overall results. In addition, considering both water and wastewater systems in an environmental assessment will help decisionmakers select a better WDMP for their case study. Thus, it could be worthwhile to include other parts of a water supply system, such as a pump station, water treatment plant, water distribution networks, in a system boundary of thorough research.

\section{Declarations}

\section{Acknowledgment}


We appreciate Mr. Mohsen Hajibabaei, a research associate at the University of Innsbruck in Austria, who spent his precious time helping and supporting us in recognizing the LCA methodology and SimaPro software. Also, we acknowledge two water and wastewater utilities of Isfahan province and Baharestan city for providing valuable data and their advice regarding the applying WDMPs.

\section{Statements and Declarations}

Ethical Approval: Ethical responsibilities of authors are approved.

Consent to Participate: All the authors agreed with the content.

Consent to Publish: All authors agreed with submission and publishing.

Authors Contributions: All authors contributed to the study conception and design. Material preparation, data collection and analysis were performed by Haniye Safarpour. The first draft of the manuscript was written by Haniye Safarpour and all authors commented on previous versions of the manuscript. All authors read and approved the final manuscript, Haniye Safarpour, Massoud Tabesh, and Seyyed Ahmadreza Shahangian.

Funding: The authors declare that no funds, grants, or other support were received during the preparation of this manuscript.

Competing Interests: The authors have no relevant financial or non-financial interests to disclose.

Availability of data and materials: Supplementary information related to this article are attached.

\section{References}

1. Akhundi A, Nazif S (2020) Life-Cycle Assessment of Tertiary Treatment Technologies to Treat Secondary Municipal Wastewater for Reuse in Agricultural Irrigation, Artificial Recharge of Groundwater, and Industrial Usages. J Environ Eng 146:4020031. https://doi.org/10.1061/(ASCE)EE.1943-7870.0001690

2. Awad H, Gar Alalm M, El-Etriby HK (2019) Environmental and cost life cycle assessment of different alternatives for improvement of wastewater treatment plants in developing countries. Sci Total Environ 660:57-68. https://doi.org/https://doi.org/10.1016/j.scitotenv.2018.12.386

3. Baharestan water and wastewater utility (2019) Personal communication

4. Bailey O, Arnot TC, Blokker EJM, Kapelan Z, Vreeburg J, Hofman JAMH (2019) Developing a stochastic sewer model to support sewer design under water conservation measures. J Hydrol 573:908-917. https://doi.org/10.1016/J.JHYDROL.2019.04.013

5. Beygi S, Tabesh M, Liu S, Safarpour H (2021) Effects of Considering Social Costs in Different Economic Scenarios of Water Systems in Iran. Int J Environ Res. https://doi.org/10.1007/s41742021-00343-Z 
6. Chaosakul T, Koottatep T, Polprasert C (2014) A model for methane production in sewers. J Environ Sci Heal Part A 49:1316-1321. https://doi.org/10.1080/10934529.2014.910071

7. Corominas L, Byrne DM, Guest JS, Hospido A, Roux P, Shaw A, Short MD (2020) The application of life cycle assessment (LCA) to wastewater treatment: A best practice guide and critical review. Water Res 184:116058. https://doi.org/https://doi.org/10.1016/j.watres.2020.116058

8. DeZellar JT, Maier WJ (1980) Effects of Water Conservation on Sanitary Sewers and Wastewater Treatment Plants. J Water Pollut Control Fed. 52, 76-88. Retrieved from http://www.jstor.org/stable/25040552

9. EPA (2010) Greenhouse Gas Emissions Estimation Methodologies for Biogenic Emissions from Selected Source Categories: Solid Waste Disposal Wastewater Treatment Ethanol Fermentation, Sector Policies and Programs Division. Measurement Policy Group, US EPA. EPA Contract No. EP-D06-118

10. Gallego-Schmid A, Tarpani RRZ (2019) Life cycle assessment of wastewater treatment in developing countries: A review. Water Res 153:63-79. https://doi.org/10.1016/j.watres.2019.01.010

11. Goette L, Leong C, Qian N (2019) Motivating household water conservation: A field experiment in Singapore. PLoS ONE 14:e0211891. https://doi.org/10.1371/journal.pone.0211891

12. Gohari A, Eslamian S, Mirchi A, Abedi-Koupaei J, Massah Bavani A, Madani K (2013) Water transfer as a solution to water shortage: A fix that can Backfire. J Hydrol 491:23-39. https://doi.org/https://doi.org/10.1016/j.jhydrol.2013.03.021

13. Hajibabaei M, Hesarkazzazi S, Lima M, Gschösser F, Sitzenfrei R (2020) Environmental assessment of construction and renovation of water distribution networks considering uncertainty analysis. Urban Water J 17:723-734. https://doi.org/10.1080/1573062X.2020.1783326

14. Hajibabaei M, Nazif S, Tavanaei Sereshgi F (2018) Life cycle assessment of pipes and piping process in drinking water distribution networks to reduce environmental impact. Sustain Cities Soc 43:538-549. https://doi.org/https://doi.org/10.1016/j.scs.2018.09.014

15. Hsien C, Choong Low JS, Chan Fuchen S, Han TW (2019) Life cycle assessment of water supply in Singapore - A water-scarce urban city with multiple water sources. Resour Conserv Recycl 151:104476. https://doi.org/https://doi.org/10.1016/j.resconrec.2019.104476

16. IPCC Guidelines for National Greenhouse Gas Inventories, Volume 5: Intergovernmental Panel on Climate Change (IPCC), Waste (2006) http://www.ipcc-nggip.iges.or.jp, Accessed 1 December 2019

17. Intergovernmental Panel on Climate Change (IPCC) (2014) Global Warming Potential Values. Greenhouse Gas Protocol, fifth assessment report, www.ipcc.ch Accessed 10 March 2020

18. International Standard (1997) ISO 14040: Environmental Management - Life Cycle Assessment Principles and Framework, Geneva, Switzerland

19. International Standard (2006) ISO 14044: Environmental Management - Life Cycle Assessment Life Cycle Impact Interpretation. International Standard Organization Geneva, Switzerland 20. Isfahan Water and Wastewater Company (2019) Unpublished results 
21. Jeong H, Broesicke OA, Drew B, Li D, Crittenden JC (2016) Life cycle assessment of low impact development technologies combined with conventional centralized water systems for the City of Atlanta, Georgia. Front Environ Sci Eng 10:1. https://doi.org/10.1007/s11783-016-0851-0

22. Jin $Y(2019)$ Estimating life cycle emissions in managing practical sewer pipeline projects. J Environ Manage 231:605-611. https://doi.org/https://doi.org/10.1016/j.jenvman.2018.10.055

23. Kalbusch A, Ghisi E (2016) Comparative life-cycle assessment of ordinary and water-saving taps. J Clean Prod 112:4585-4593. https://doi.org/https://doi.org/10.1016/j.jclepro.2015.06.075

24. Kyung D, Kim D, Yi S, Choi W, Lee W (2017) Estimation of greenhouse gas emissions from sewer pipeline system. Int J Life Cycle Assess 22:1901-1911. https://doi.org/10.1007/s11367-017-1288-9

25. Liu A, Mukheibir $P$ (2018) Digital metering feedback and changes in water consumption - A review. Resour Conserv Recycl 134:136-148. https://doi.org/10.1016/J.RESCONREC.2018.03.010

26. Lopes TA, de Queiroz S, Kiperstok LM A (2018) Environmental performance of a full-scale wastewater treatment plant applying Life Cycle Assessment. https://doi.org/10.4136/ambiagua.2216. Rev Ambient Água

27. Lopez-Nicolas A, Pulido-Velazquez M, Rougé C, Harou JJ, Escriva-Bou A (2018) Design and assessment of an efficient and equitable dynamic urban water tariff. Application to the city of Valencia, Spain. https://doi.org/10.1016/j.envsoft.2017.12.018. Environ Model Softw

28. Mannan M, Al-Ghamdi SG (2020) Environmental impact of water-use in buildings: Latest developments from a life-cycle assessment perspective. J Environ Manage 261:110198. https://doi.org/https://doi.org/10.1016/j.jenvman.2020.110198

29. Marinoski AK, Rupp RF, Ghisi E (2018) Environmental benefit analysis of strategies for potable water savings in residential buildings. J Environ Manage 206:28-39.

https://doi.org/10.1016/J.JENVMAN.2017.10.004

30. Marleni N, Gray S, Sharma A, Burn S, Muttil N (2015) Impact of water management practice scenarios on wastewater flow and contaminant concentration. J Environ Manage 151:461-471. https://doi.org/10.1016/J.JENVMAN.2014.12.010

31. Morera S, Remy C, Comas J, Corominas L (2016) Life cycle assessment of construction and renovation of sewer systems using a detailed inventory tool. Int J Life Cycle Assess 21:1121-1133. https://doi.org/10.1007/s11367-016-1078-9

32. Opher T, Friedler E (2016) Comparative LCA of decentralized wastewater treatment alternatives for non-potable urban reuse. J Environ Manage 182:464-476. https://doi.org/https://doi.org/10.1016/j.jenvman.2016.07.080

33. Parkinson J, Schütze M, Butler D, MODELLING THE IMPACTS OF DOMESTIC WATER CONSERVATION ON THE SUSTAIN ABILITY OF THE URBAN SEWERAGE SYSTEM (2005) Water Environ J 19:49-56. https://doi.org/10.1111/j.1747-6593.2005.tb00548.x

34. Petit-Boix A, Devkota J, Phillips R, Vargas-Parra MV, Josa A, Gabarrell X, Rieradevall J, Apul D (2018) Life cycle and hydrologic modeling of rainwater harvesting in urban neighborhoods: Implications of 
urban form and water demand patterns in the US and Spain. Sci Total Environ 621:434-443. https://doi.org/https://doi.org/10.1016/j.scitotenv.2017.11.206

35. Petit-Boix A, Roigé N, de la Fuente A, Pujadas P, Gabarrell X, Rieradevall J, Josa A (2016) Integrated Structural Analysis and Life Cycle Assessment of Equivalent Trench-Pipe Systems for Sewerage. Water Resour Manag 30:1117-1130. https://doi.org/10.1007/s11269-015-1214-5

36. Petit-Boix A, Sanjuan-Delmás D, Chenel S, Marín D, Gasol CM, Farreny R, Villalba G, Suárez-Ojeda ME, Gabarrell X, Josa A, Rieradevall J (2015) Assessing the Energetic and Environmental Impacts of the Operation and Maintenance of Spanish Sewer Networks from a Life-Cycle Perspective. Water Resour Manag 29:2581-2597. https://doi.org/10.1007/s11269-015-0958-2

37. Piao W, Kim Y, Kim H, Kim M, Kim C (2016) Life cycle assessment and economic efficiency analysis of integrated management of wastewater treatment plants. J Clean Prod 113:325-337. https://doi.org/https://doi.org/10.1016/j.jclepro.2015.11.012

38. Pishyar S, Khosravi H, Tavili A, Malekian A (2018) Desertification Risk Mapping based on Water Resources Degradation using Multi Criteria Decision Making (Case Study: Kashan Plain) TT JSTNAR. 21:71-84. https://doi.org/10.29252/jstnar.21.4.71

39. Quesnel KJ, Ajami NK (2017) Changes in water consumption linked to heavy news media coverage of extreme climatic events. Sci Adv 3. https://doi.org/10.1126/sciadv.1700784

40. Ramsey E, Berglund EZ, Goyal R (2017) The Impact of Demographic Factors, Beliefs, and Social Influences on Residential Water Consumption and Implications for Non-Price Policies in Urban India. https://doi.org/10.3390/w9110844. Water

41. Ratnasiri S, Wilson C, Athukorala W, Garcia-Valiñas MA, Torgler B, Gifford R (2018) Effectiveness of two pricing structures on urban water use and conservation: a quasi-experimental investigation. Environ Econ Policy Stud 20:547-560. https://doi.org/10.1007/s10018-017-0205-6

42. ReCipe (2016) A Harmonized Life Cycle Impact Assessment Method at Midpoint and Endpoint Level. National Institute for Public Health and Environment

43. Resende JD, Nolasco MA, Pacca SA (2019) Life cycle assessment and costing of wastewater treatment systems coupled to constructed wetlands. Resour Conserv Recycl 148:170-177. https://doi.org/10.1016/j.resconrec.2019.04.034

44. Risch E, Gutierrez O, Roux P, Boutin C, Corominas L (2015) Life cycle assessment of urban wastewater systems: Quantifying the relative contribution of sewer systems. Water Res 77:35-48. https://doi.org/10.1016/j.watres.2015.03.006

45. Rodriguez-Garcia G, Hospido A, Bagley DM, Moreira MT, Feijoo G (2012) A methodology to estimate greenhouse gases emissions in Life Cycle Inventories of wastewater treatment plants. Environ Impact Assess Rev 37:37-46. https://doi.org/10.1016/j.eiar.2012.06.010

46. Safarpour H, Tabesh M, Shahangian SA, Hajibabaei M, Sitzenfrei R (2021) Assessment of Sewer Gas Emissions under Applying Water Demand Management and Their Effects on Global Warming. The virtual conference of AQUA $\approx 360$ : Water for All - Emerging Issues and Innovations, University of Exeter, United Kingdom 
47. Shahangian SA, Tabesh M, Safarpour H (2020) A Review of the Conceptual Framework of the Interactive Cycle and Modeling Process Used in Urban Water Management. Iran-Water Resour Res 16:63-79

48. Shahangian SA, Tabesh M, Yazdanpanah M (2021a) How can socio-psychological factors be related to water-efficiency intention and behaviors among Iranian residential water consumers? J Environ Manage 288:112466. https://doi.org/10.1016/j.jenvman.2021.112466

49. Shahangian SA, Tabesh M, Yazdanpanah M (2021b) Psychosocial determinants of household adoption of water-efficiency behaviors in Tehran capital, Iran: Application of the social cognitive theory. Urban Clim 39:100935. https://doi.org/10.1016/J.UCLIM.2021.100935

50. Sharma N, Rao B (2018) Life-cycle atmospheric emissions and energy use of the collection phase of a typical Indian sewerage system. Energy Ecol Environ 3:48-68. https://doi.org/10.1007/s40974017-0066-7

51. Slagstad H, Brattebø $H$ (2014) Life cycle assessment of the water and wastewater system in Trondheim, Norway - A case study. Urban Water J 11:323-334.

https://doi.org/10.1080/1573062X.2013.795232

52. Stavenhagen M, Buurman J, Tortajada C (2018) Saving water in cities: Assessing policies for residential water demand management in four cities in Europe.

https://doi.org/10.1016/j.cities.2018.03.008. Cities

53. Stephan A, Stephan L (2017) Life cycle water, energy and cost analysis of multiple water harvesting and management measures for apartment buildings in a Mediterranean climate. Sustain Cities Soc 32:584-603. https://doi.org/10.1016/j.scs.2017.05.004

54. Sun J, Hu S, Sharma KR, Bustamante H, Yuan Z (2015) Impact of reduced water consumption on sulfide and methane production in rising main sewers. J Environ Manage 154:307-315. https://doi.org/10.1016/j.jenvman.2015.02.041

55. Tabesh M, Feizee Masooleh M, Roghani B, Motevallian SS (2019) Life-Cycle Assessment (LCA) of Wastewater Treatment Plants: A Case Study of Tehran, Iran. Int J Civ Eng 17:1155-1169. https://doi.org/10.1007/s40999-018-0375-z

56. Tanverakul SA, Lee J (2015) Impacts of Metering on Residential Water Use in California. J Am Water Works Assoc 107:E69-E75. https://doi.org/10.5942/jawwa.2015.107.0005

57. Tee KF, Li CQ, Mahmoodian DM (2011) Prediction of Time-variant Probability of Failure for Concrete Sewer Pipes. In Proc. of the 12th International Conference on Durability of Building Materials and Components. 12-15

58. Willis RM, Stewart RA, Giurco DP, Talebpour MR, Mousavinejad A (2013) End use water consumption in households: impact of socio-demographic factors and efficient devices. J Clean Prod 60:107-115. https://doi.org/10.1016/J.JCLEPR0.2011.08.006

59. Xiong J, Zhu J, He Y, Ren S, Huang W, Lu F (2020) The application of life cycle assessment for the optimization of pipe materials of building water supply and drainage system. Sustain Cities Soc 60:102267. https://doi.org/10.1016/j.scs.2020.102267 
60. Xue X, Cashman S, Gaglione A, Mosley J, Weiss L, Ma XC, Cashdollar J, Garland J (2019) Holistic analysis of urban water systems in the Greater Cincinnati region: (1) life cycle assessment and cost implications. Water Res X 2:100015. https://doi.org/10.1016/j.wroa.2018.100015

\section{Figures}

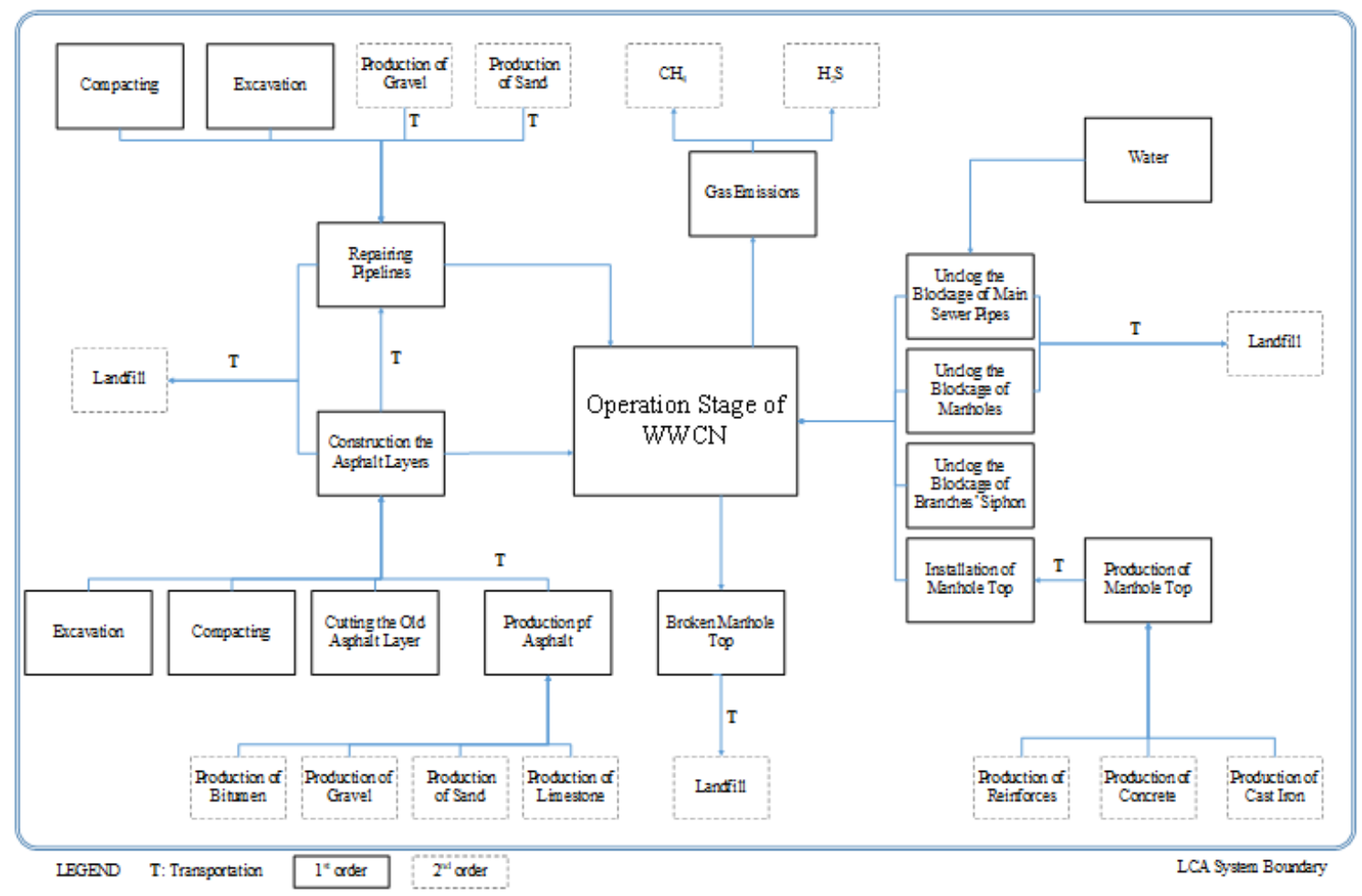

(a)

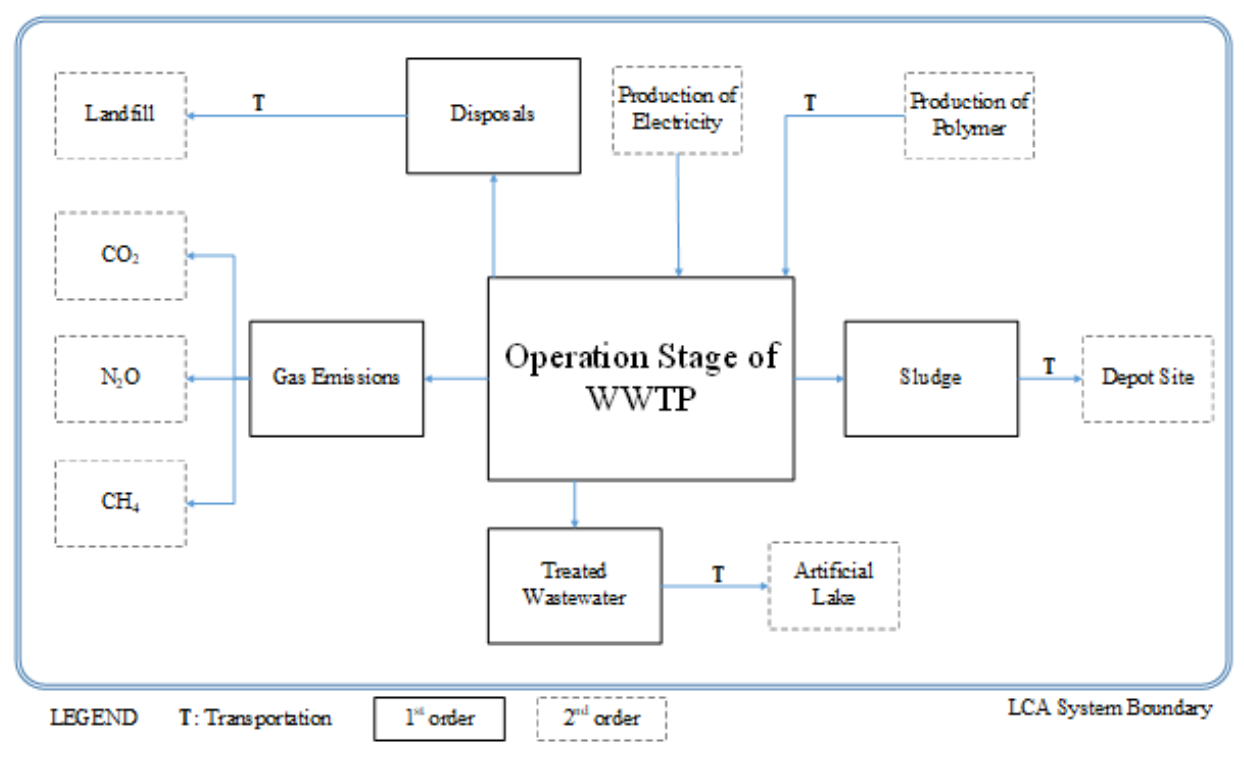

(b) 
The defined system boundary of a) the wastewater collection network (WWCN), b) the wastewater treatment plant (WWTP)
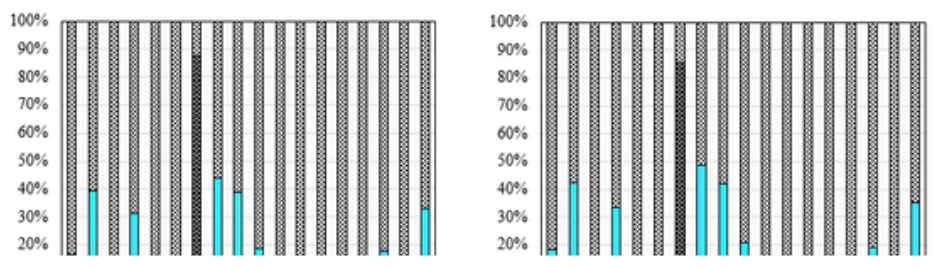

Figure 2 
Environmental impacts of WWCN's phases of a) the base scenario, b) scenario 1, c) scenario 2, d) scenario 3, e) scenario 4; all by the ReCipe midpoint method
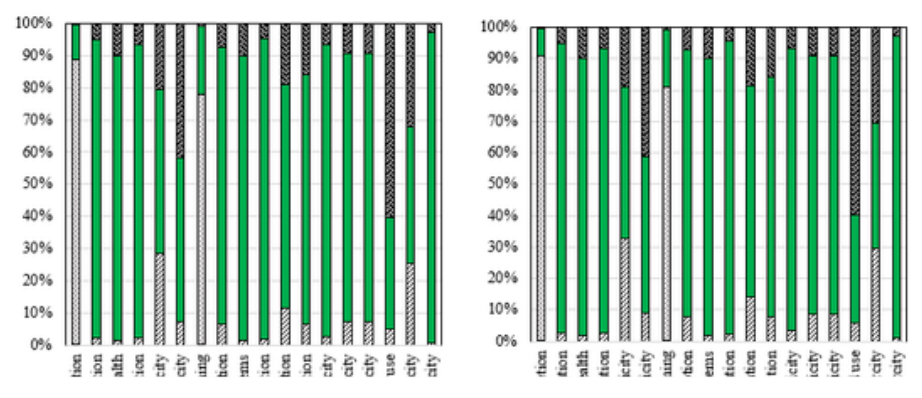

Figure 3

Environmental impacts of WWTP's phases of a) the base scenario, b) scenario 1, c) scenario 2, d) scenario 3, e) scenario 4; all by the ReCipe midpoint method 


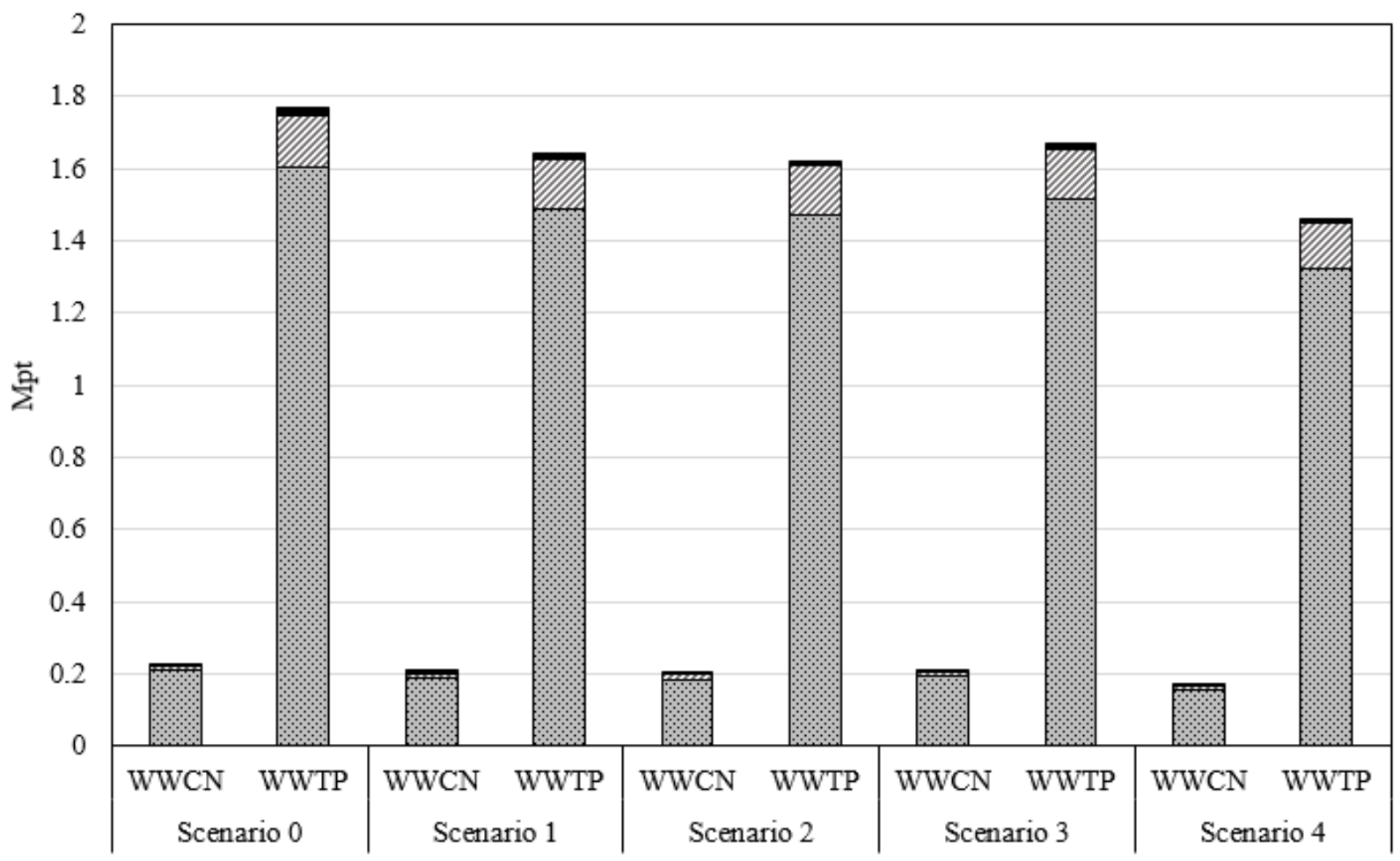

- Resources

๑ Ecosystem

․ Human health

\section{Figure 4}

Comparing environmental impacts between the WWCN and WWTP in every scenario by the ReCipe endpoint method 


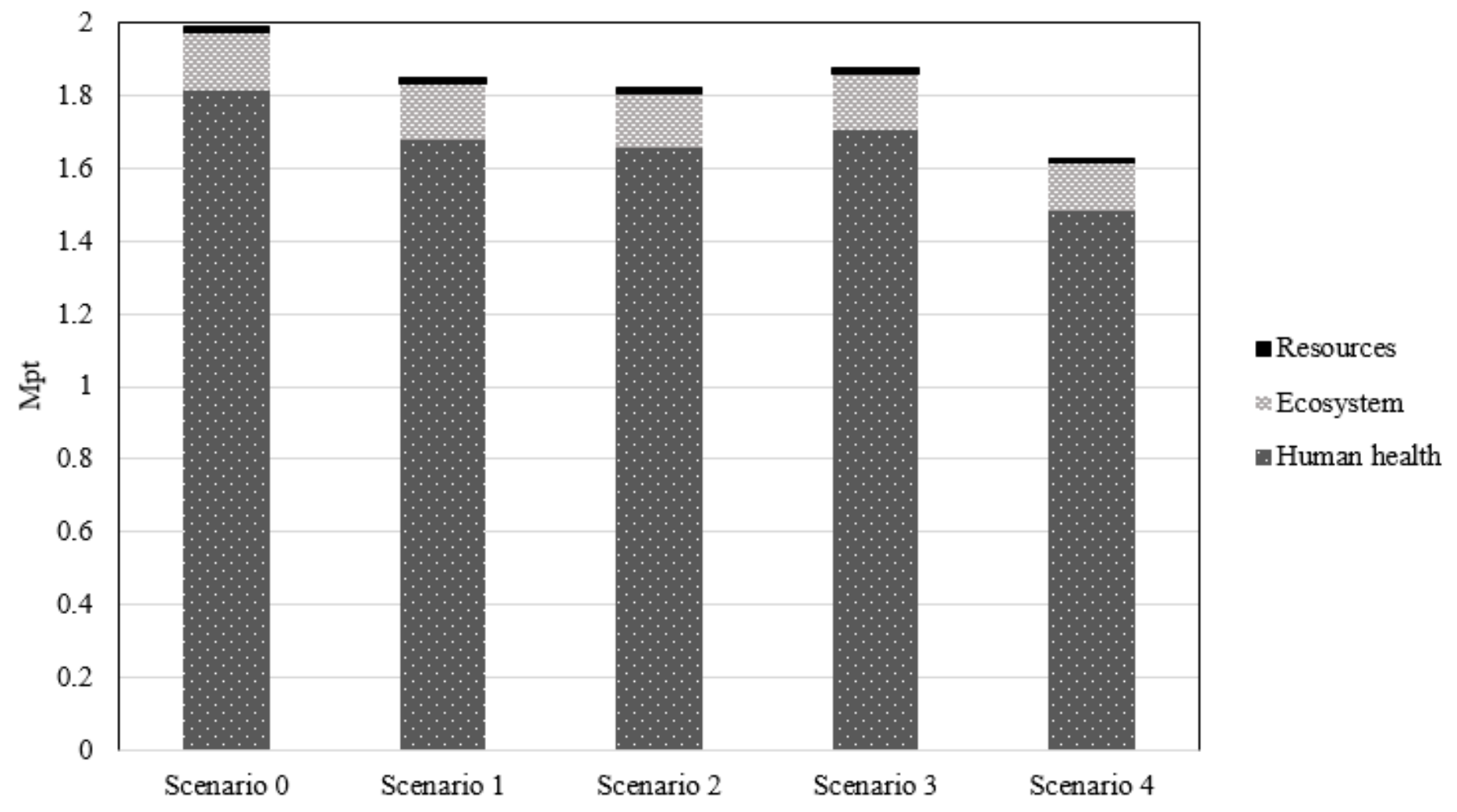

Figure 5

Environmental impacts of different scenarios by the ReCipe endpoint method

\section{Supplementary Files}

This is a list of supplementary files associated with this preprint. Click to download.

- Highlights.docx

- SupplementaryInformationSI2021.docx

- graphicalabstract.docx 